\title{
It hurts when I do this (or you do that): Posture and pain tolerance is
}

\author{
Vanessa K. Bohns* \\ J. L. Rotman School of Management, University of Toronto \\ Scott S. Wiltermuth \\ Marshall School of Business, University of Southern California
}

\begin{abstract}
A b s t r a c t
Recent research (Carney, Cuddy, \& Yap, 2010) has shown that adopting a powerful pose changes people's hormonal levels and increases their propensity to take risks in the same ways that possessing actual power does. In the current research, we explore whether adopting physical postures associated with power, or simply interacting with others who adopt these postures, can similarly influence sensitivity to pain. We conducted two experiments. In Experiment 1, participants who adopted dominant poses displayed higher pain thresholds than those who adopted submissive or neutral poses. These findings were not explained by semantic priming. In Experiment 2, we manipulated power poses via an interpersonal interaction and found that power posing engendered a complementary (Tiedens \& Fragale, 2003) embodied power experience in interaction partners. Participants who interacted with a submissive confederate displayed higher pain thresholds and greater handgrip strength than participants who interacted with a dominant confederate.
\end{abstract}

Keywords: Complementarity, Dominance, Embodiment, Interpersonal relations, Power, Pain

The management of pain has presented an enduring puzzle for medical patients, practitioners, and researchers alike because the experience of pain is not only extremely distressing, but also highly subjective. Indeed, pain appears to be as psychological as it is physiological (Wager et al., 2004, 2007) and both individual differences (Mogil, 1999) and contextual factors (Price, 2000) affect how individuals experience pain. Pain researchers have examined the role of selfefficacy beliefs and perceptions of control as determinants of pain tolerance (Bandura, O'Leary, Taylor, Gauthier, \& Gossard, 1987; Litt, 1988). We explore whether simply adopting physical postures associated with power or interacting with others who adopt these postures can similarly influence sensitivity to pain. In examining these issues, the present research fuses research on embodied power (Carney et al., 2010; Huang et al., 2011) with research on interpersonal complementarity (Tiedens \& Fragale, 2003) to hypothesize that a factor as subtle as the way an interaction partner (e.g., a doctor, a significant other) is standing (i.e., in a high or low power position) can affect an individual's pain threshold.

\footnotetext{
is The authors contributed equally and are listed alphabetically. We would like to thank Justin Fan and Kristin Jung for their considerable help in administering the experiments. We note that Justin illustrated the postures in Figure 3.

* Corresponding author. E-mail addresses: Vanessa.Bohns@rotman.utoronto.ca (V.K. Bohns), wiltermu@usc.edu (S.S. Wiltermuth).
} 
Attributes related to physical toughness (Dienstbier, 1989), such as physical strength and resistance to pain, have traditionally been seen as causes, not effects, of dominance displays (Hall, Coats, \& Smith LeBeau, 2005). Across species, individuals who are physically strong and/or "alpha" members of the social pecking order typically signal their power through expansive postures that take up more space and intrude into others' personal territory (Carney, Hall, \& Smith LeBeau, 2005; Darwin, 2009; de Waal, 1998; Eibl-Eibesfeldt, 1975). Yet recent research suggests that the nature of the relationship between actual power and displays of power may be bidirectional. Carney and colleagues (2010) found that postures associated with power can produce elements of actual power. Specifically, adopting expansive postures led to the hormonal changes (i.e., increased testosterone, decreased cortisol) and increased propensity for risk-taking associated with power, while adopting constrictive positions had the opposite effect. Relatedly, Schubert and Koole (2009) found that making a fist led men to perceive themselves as more assertive and esteemed.

Postures associated with dominance and power may similarly affect how people experience pain. Both objective and subjective experiences of power engender perceptions of control, i.e., "the availability of a response" (Litt, 1988, p. 149), and self-efficacy, i.e., "one's confidence in one's ability to effect that response" (Fast, Gruenfeld, Sivanathan, \& Galinsky, 2009; Keltner, Gruenfeld, \& Anderson, 2003). In one study, individuals who reported engaging in more submissive behaviors in their relationships also reported lower perceptions of pain control (Lackner \& Gurtman, 2004). Further, perceptions of control and self-efficacy have been linked to reduced sensitivity to pain (Averill, 1973; Bandura et al., 1987; Holroyd et al., 1984; Litt, 1988). For instance, perceptions of control and self-efficacy have been shown to affect sensitivity to pain during childbirth (Manning \& Wright, 1983).

Given that posing as if one possesses power produces many of the same effects as actually possessing power, and that possessing power heightens perceptions of control and self-efficacy that decrease one's sensitivity to pain, adopting postures associated with dominance should reduce sensitivity to pain. In support of this embodiment rationale, the hormones associated with power posing (Carney et al., 2010) have been linked to both self-efficacy and pain. Testosterone has been associated with expectations of success and overconfidence (Johnson et al., 2006), as well as higher pain tolerance (Hau, Dominguez, \& Evrard, 2004; Hellstroem \& Lundberg, 2000). Elevated cortisol, which is associated with low power, is a response to pain, though the effect of cortisol on pain perception - the focus of the current research - remains unclear (Al'Absi, Peterson, \& Wittmers, 2002). Altogether, these hormone data corroborate our proposed link between power posing, self-efficacy, and pain tolerance.

Although we are particularly interested in the extent to which high-versus low-power participants experience a stimulus as aversive, rather than their willingness to tolerate uncomfortable stimuli (Keltner et al., 2003), it is worth noting that power-approach theory may offer a similar prediction: Low-power individuals display greater attention to, and anticipation of, threat and punishment. Pain intensity has been shown to increase with greater attention to (McCaul \& Malott, 1984) and anticipation of (Bandura, Reese, \& Adams, 1982) aversive stimuli. Thus, power-approach theory would also predict that low-power individuals should exhibit lower pain tolerance.

The current research seeks to identify whether power posing influences an individual's pain threshold through two means - one intrapersonal, and one interpersonal. Experiment 1 tested the hypothesis that posing individuals in postures associated with dominance (submissiveness) would increase (decrease) their pain thresholds. Experiment 2 tested a 
second hypothesis that individuals would spontaneously adopt such postures to complement an interaction partner's behavior and would consequently experience the same physiological effects as in Experiment 1.

\section{Experiment 1}

Eighty-nine participants ( 44 female) were told they were participating in a study about the health benefits of exercise at work and that they would be adopting a series of yoga poses. Participants were randomly assigned to one of three postural conditions: an expansive posture associated with dominance, a constricted posture associated with submissiveness, or control (Fig. 1). These poses were chosen based on Tiedens and Fragale's (2003) description of nonverbal dominance as expansive ("moving one's limbs out from oneself") and submissiveness as constricted ("curving the torso inwards"; p. 558). To confirm that the poses conveyed dominance and submissiveness, 27 pre-test participants rated both the dominant and the submissive poses on a scale from 1 (not dominant at all) to 7 (very dominant). Participants rated the expansive pose as significantly more dominant $(M=4.07, S D=1.64)$ than the constricted pose $(M=2.22, S D=$ 1.63), $\mathrm{t}(26)=3.84, \mathrm{p}<.01, \mathrm{r}=.49$ Further, pre-test results indicated that the expansive and constricted postures did not differ on the dimensions of discomfort $(\mathrm{t}(26)=1.28, p=.21)$, difficulty $(\mathrm{t}(26)=1.47, p=.15)$, or painfulness $(\mathrm{t}(26)=-.80, p$ $=.43)$.

To measure pain threshold, we used the tourniquet technique (Benedetti, 1996; Smith, Egbert, Markowitz, Mosteller, \& Beecher, 1966, 1972, Smith, Lowenstein, Hubbard, \& Beecher, 1972). Under the guise of our cover story, participants donned a blood pressure cuff. The experimenter then inflated the cuff at a fixed rate, which induced pain by reducing blood flow to the participant's arm. Participants were instructed to say "stop" when they experienced discomfort from the pressure. Pain threshold was recorded in millimeters of mercury ( $\mathrm{mmHg}$ ), which is the traditional unit used to report blood pressure.

After completing the pain threshold test, participants were tasked to hold their assigned yoga pose for twenty seconds. Finally, they repeated the pain threshold test. This design allowed us to assess changes in pain threshold from baseline resulting from the posture manipulation. ${ }^{1}$

\section{Results}

We predicted that participants in the dominant pose condition would display a higher pain threshold than participants in either the submissive or neutral pose conditions. To test this prediction, we regressed post-manipulation pain threshold on dummy variables representing the neutral and submissive pose conditions, controlling for gender and baseline pain threshold. This regression allowed us to test the effect of posture condition on pain threshold. Participants' post manipulation pain thresholds were lower in the neutral $(B=-20.28, S E=8.58, t(83)=2.63, p=.02)$ and submissive $(B=$ $-16.87, S E=8.49, \mathrm{t}(83)=1.99, p=.05)$ conditions than in the dominant condition. The submissive and neutral conditions were not significantly different from one another. Males' post-manipulation pain thresholds were marginally higher

\footnotetext{
${ }^{1}$ This repeated-measure design allowed us to control for individual variations in pain threshold. However, it left open the possibility that people who adopt postures associated with dominance would be more likely to strive for improvement on tasks - regardless of whether the task involves sensitivity to pain.
} 
(controlling for initial pain thresholds) than females', $\mathrm{B}=7.00, \mathrm{SE}=3.60, \mathrm{t}(83)=1.95, p=.06$. Fig. 2 uses difference scores to display the pattern of our findings.

\section{Addendum to Experiment 1}

To ensure our findings in Experiment 1 were not due to priming effects, we ran 60 participants in two additional conditions. These participants completed the same procedure described in Experiment 1, but rather than physically adopting the poses, they viewed pictures of the poses and rated the quality of the artwork and the clarity of the text used in the materials. ${ }^{2}$ After participants provided these ratings, we measured pain threshold with the tourniquet technique used in Experiment 1. Unlike participants who adopted the poses, participants who simply viewed pictures of a dominant pose did not show an increase in pain threshold relative to participants who viewed a submissive pose, $B=-0.75, S E$ $=7.00, \mathrm{t}(56)=0.11, p=.92$.

\section{Experiment 2}

In Experiment 2, we tested our second hypothesis that an individual's sense of embodied power, and resulting sensitivity to pain, would be affected by the behaviors of that individual's interaction partner. Consistent with interpersonal theory (Kiesler, 1983; Leary, 1957; Wiggins, 1982), research has shown that when one interaction partner displays a "power pose" (an expansive, open posture), the other interaction partner is likely to display a submissive pose in response (a constricted, closed posture) (Drews, 1993; Tiedens \& Fragale, 2003). This tendency to behave complementarily should therefore have physical repercussions for both interaction partners. That is, adopting a dominant or submissive posture should also affect the physical experience (pain threshold) of one's interaction partner.

We hypothesized that interacting with a "power posing" partner would engender a complementary experience of embodied power. Specifically, we hypothesized that interacting with a dominant confederate would lead participants to display lower pain thresholds (as a result of adopting the complementary constricted posture) than participants who interacted with a submissive confederate.
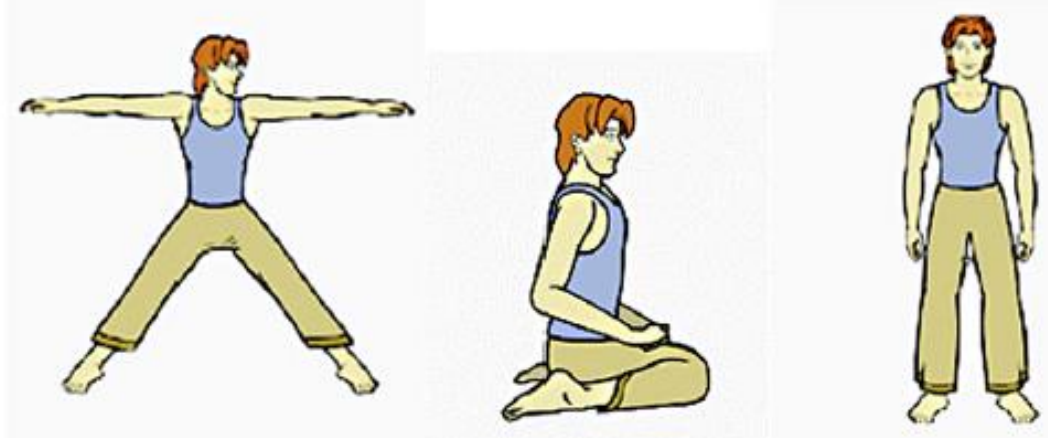

Fig. 1. Stimuli used in Experiment 1. Participants were shown and asked to adopt one of these three yoga poses (conditions from left to right: dominant, submissive, and control),

2 Complementarity is a motivated process and complementary responses are related to a desire for smooth interactions (Tiedens et al., 2007). Participants did not expect to interact with cartoon stimuli; consequently, we would not expect the images to evoke complementarity (see also Cesario et al., 2006). 




Fig. 2 Change in pain threshold (depicted as difference scores; statistical analysis examined time 2 controlling for time 1; error bars are SEs).

\section{Procedure}

We adapted a procedure used by Tiedens and Fragale (2003). Thirty participants (12 female) were told they were participating in a study on relaxation that would require them to look at a series of nature photographs. We again measured pain threshold by means of the tourniquet technique. We also administered a handgrip strength test. Participants were asked to squeeze a hand dynamometer as hard as they could for twenty seconds. Average handgrip strength was recorded in Newtons. ${ }^{3}$

We first took baseline measures of pain threshold and grip strength. Participants then engaged in a picture description task with a confederate. The participant and the confederate took turns describing nature images projected on the walls behind the heads of their counterparts. In half of the sessions, confederates displayed dominance for the duration of the interaction by enacting behaviors that Hall et al.'s (2005) meta-analysis showed to be associated with dominance. Specifically, they maintained open body postures, spoke loudly, and reduced the physical space between themselves and their counterparts. In the remaining sessions, confederates displayed submissiveness throughout the interaction by maintaining closed body postures, speaking softly, and preserving the physical space between themselves and their counterparts. Fig. 3 displays the postures adopted by the confederate. Participants were paired with a same gender confederate. The experimenter left the room during this interaction to remain blind to condition. After this task, we readministered the pain threshold and grip strength measures. During debriefs, no participants reported any suspicion that the other participant was a confederate, and none guessed that we were interested in their or the confederate's posture, demeanor, or aggressiveness.

\section{Additional measure}

Twenty-four of the confederate-participant interactions were videotaped. Two independent coders, blind to condition and hypotheses, watched each videotape and rated how submissively the participant behaved on a seven-point Likerttype scale (1: not submissively at all; 7: very submissively).

\footnotetext{
3 A Newton is the force required to accelerate one kilogram per meter per second per second. It takes about $25 \mathrm{~N}$ of force to break an egg.
} 
Results

We regressed post-manipulation pain threshold on baseline pain threshold and a dummy variable representing the dominant condition. (There were no gender effects in this experiment.) Consistent with our predictions, participants' pain thresholds were lower after interacting with a dominant confederate than they were after interacting with a submissive confederate, $\mathrm{B}=-20.46, \mathrm{SE}=9.18, \mathrm{t}(26)=2.23, p=.04$. Fig. 4 displays differences in mean pain thresholds by condition.

We also regressed post-manipulation grip strength on baseline grip strength and a dummy variable representing the dominant condition. Participants' handgrip strengths were lower after interacting with a dominant confederate than they were after interacting with a submissive confederate, $\mathrm{B}=-37.73, \mathrm{SE}=17.62, \mathrm{t}(26)=2.14, p=.04$. Fig. 5 displays differences in handgrip strength by condition.

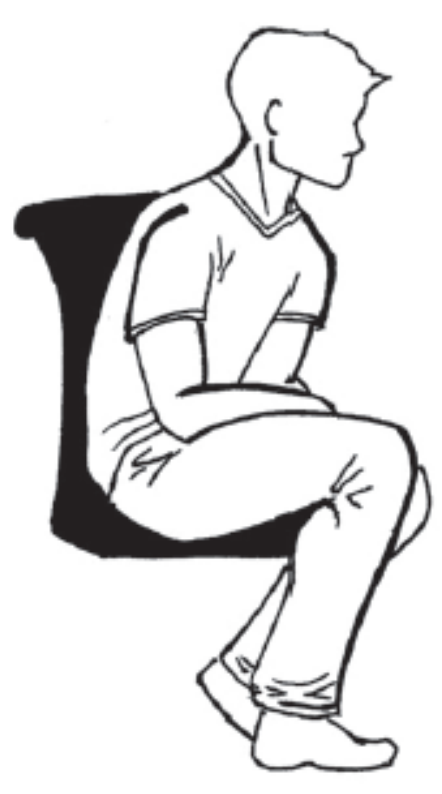

Submissive

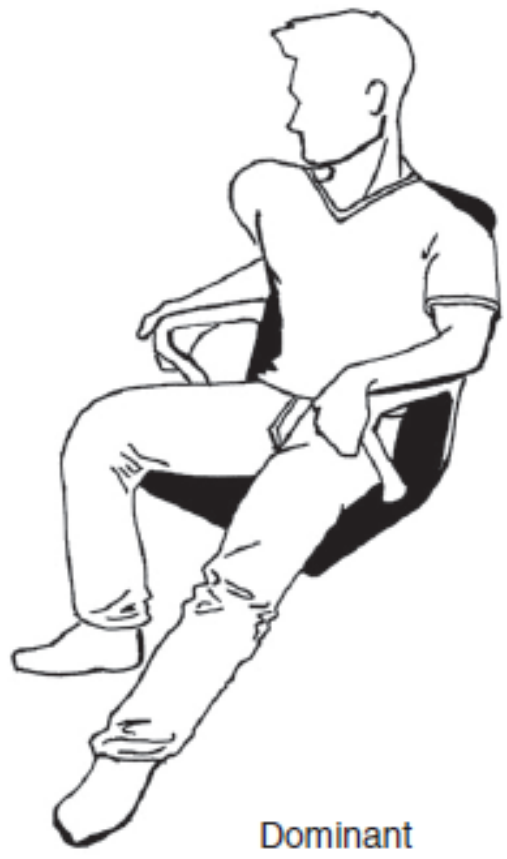

Dominant

Fig 3. Postures exhibited by confederate in Experiment 2.

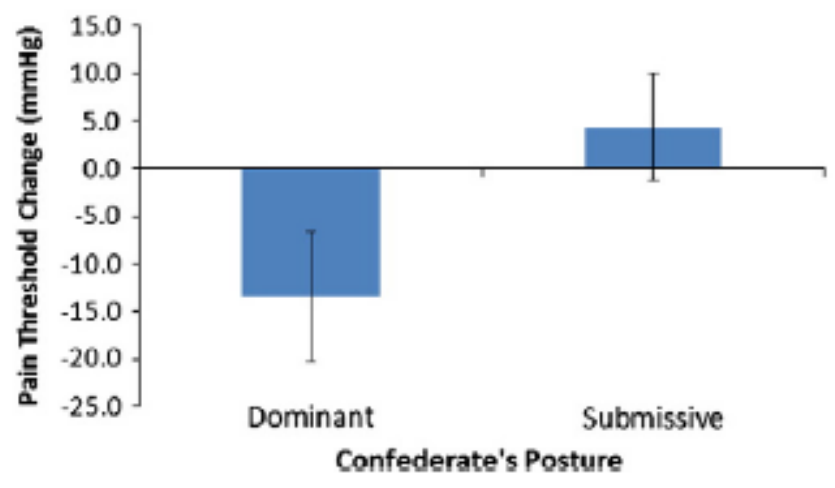

Fig 4. Change in pain threshold (depicted as difference scores; statistical analysis examined time 2 controlling for time 1 ; error bars are SEs). 
Videotape coding $(a=.70)$ confirmed that participants behaved more submissively when paired with a dominant confederate $(M=3.35, S D=1.45)$ than with a submissive confederate $(M=2.23, S D=1.04), t(22)=2.18, p=.04$. However, rated submissiveness did not affect post-manipulation pain threshold after controlling for condition and pre-manipulation pain threshold, $p=.60$, nor postmanipulation handgrip strength after controlling for condition and pre-manipulation handgrip strength, $p=.90$.

\section{Discussion}

In two experiments, we found that power posing was associated with higher pain thresholds when individuals (1) were instructed to adopt power poses, or (2) adopted power poses spontaneously in response to an interaction partner's behavior. Experiment 1 suggests that power posing may be a useful tool for pain management. Even individuals who do not perceive themselves as having control over their circumstances may benefit from behaving as if they do by adopting power poses. Experiment 2 suggests that subtle interpersonal interactions with caregivers and doctors may also influence an individual's pain tolerance through the process of dominance complementarity.

Although embodied power appears to be driving these results, some limitations of the current studies suggest a need for additional research to clarify the specific mechanism. First, the greater muscle tension required to hold the dominant pose in Experiment 1 may have had an unintended physiological effect related to pain. While greater effort would have caused participants to experience more arm weakness in the dominant condition in Experiment 1, suggesting this test was conservative, there may be additional physiological considerations worth examining. Second, in Experiment 2, videotape coding of submissiveness did not mediate our effects; i.e., the number of submissive or dominant behaviors a participant exhibited was not associated with increased pain tolerance. Since we did not measure self-efficacy directly in either study, we cannot rule out the possibility that our Experiment 2 findings reflect a psychological effect of interacting with a dominant or submissive confederate, rather than embodied power.

Despite these limitations, the current studies make an important theoretical contribution by integrating an interpersonal complementarity approach with embodied power research. Interpersonal circumplex research has traditionally been concerned with interpersonal variables, such as liking and relationship satisfaction. However, the current research suggests that there may also be intrapersonal psychological and physiological consequences of complementary interactions. To our knowledge, no research has previously examined the link between complementary behavior and embodiment. Rather, prior research on the interpersonal nature of embodiment has been consistent with a behavioral mimicry account (Chartrand \& Bargh, 1999; Hsee et al., 1990; Vaughn \& Lanzetta, 1981). Explorations of the interpersonal dynamics of embodiment such as these may be an important means of integrating social psychology with embodiment research (cf., Schubert \& Semin, 2009).

The current research also supports interpersonal circumplex theory as a useful framework for preserving the inherent social nature of power within embodied power research. A key theoretical contribution comes from the design of Experiment 2, which pitted a prediction based on a power prime - i.e., the participant's pain response will be consistent with the behaviors of the confederate - against a prediction based on interpersonal complementarity and embodied 
power-i.e., the participant's pain response will be consistent with behaviors complementary to those of the confederate. Results were consistent with the complementarity hypothesis. This finding highlights the dynamic social and interpersonal nature of embodied power. Simply perceiving or thinking about a powerful person should have different psychological and physiological effects than actually interacting with that person.

\section{References}

Al'Absi, M., Peterson, K. L., \& Wittmers, L. E. (2002). Adrenocortical and hemodynamic predictors of pain perception in men and women. Pain, 96,197-204.

Averill, J. R. (1973). Personal control over aversive stimuli and its relationship to stress. Psychological Bulletin, 80, 286-303.

Bandura, A., O'Leary, A., Taylor, C. B., Gauthier, J., \& Gossard, D. (1987). Perceived self efficacy and pain control: Opioid and non-opioid mechanisms. Journal of Personality and Social Psychology, 53, 563-571.

Bandura, A., Reese, L.,\&Adams, N. E. (1982). Microanalysis of action and fear arousal as a function of differential levels of perceived self-efficacy. Journal of Personality and Social Psychology, 43, 5-21.

Benedetti, F. (1996). The opposite effects of the opiate antagonist naloxone and the cholecystokinin antagonist proglumide on placebo analgesia. Pain, 64, 535-543.

Carney, D., Cuddy, A. J. C., \& Yap, A. (2010). Power posing: Brief nonverbal displays affect neuroendocrine levels and risk tolerance. Psychological Science, 21, 1363-1368.

Carney, D. R., Hall, J. A., \& Smith LeBeau, L. (2005). Beliefs about the nonverbal expression of social power. Journal of Nonverbal Behavior, 29,105-123.

Cesario, J., Plaks, J. E., \& Higgins, E. T. (2006). Automatic social behavior as motivated preparation to interact. Journal of Personality and Social Psychology, 90, 893-910.

Chartrand, T. L., \& Bargh, J. A. (1999). The chameleon effect: The perception-behavior link and social interaction. Journal of Personality and Social Psychology, 76,893-910.

Darwin, C. (2009). The expression of the emotions in man and animals. New York, NY: Oxford (Original work published 1872).

de Waal, F. (1998). Chimpanzee politics: Power and sex among apes. Baltimore, MD: Johns Hopkins University Press.

Dienstbier, R. A. (1989). Arousal and physiological toughness: Implications for mental and physical health. Psychological Review, 96(1), 84-100.

Drews, C. (1993). The concept and definition of dominance in animal behaviour. Behaviour, 125, 283-313.

Eibl-Eibesfeldt, I. (1975). Ethology: The biology of human behavior. New York: Holt, Rinehart \& Winston.

Fast, N. J., Gruenfeld, D. H., Sivanathan, N., \& Galinsky, A. D. (2009). Illusory control: A generative force behind power's far-reaching effects. Psychological Science, 20, 502-508.

Hall, J. A., Coats, E. J., \& Smith LeBeau, L. (2005). Nonverbal behavior and the vertical dimension of social relations: A meta-analysis. Psychological Bulletin, 131, 898-924. 
Hau, M., Dominguez, O. A., \& Evrard, H. C. (2004). Testosterone reduces responsiveness to nociceptive stimuli in a wild bird. Hormones and Behavior, 46,165-170.

Hellstroem, B., \& Lundberg, U. (2000). Pain perception to the cold pressor test during the menstrual cycle in relation to estrogen levels and a comparison to men. Integrative Physiological and Behavioral Science, 35,132-141.

Holroyd, K. A., Penzien, D. B., Hursey, K. G., Tobin, D. L., Rogers, L., Holm,J. E., Marcille, P.J., Hall, J. R., \& Chila, A. G. (1984). Change mechanisms in EMG biofeedback training: Cognitive changes underlying improvements in tension headache. Journal of Consulting and Clinical Psychology, 52,1039-1053.

Hsee, C. K., Hatfield, E., Carlson, J., \& Chemtob, C. (1990). The effect of power on susceptibility to emotional contagion. Cognition and Emotion, 4, 327-340.

Huang, L., Galinsky, A. D., Gruenfeld, D. H., \& Guillory, L. E. (2011). Powerful Postures vs. Powerful Roles: Which is the Proximate Correlate of Thought and Behavior? Psychological Science, 22, 95-102.

Johnson, D. D., McDermott, R., Barrett, E. S., Cowden,J., Wrangham, R., Mclntyre, M. H., \& Rosen, P. S. (2006). Overconfidence in wargames: Experimental evidence on expectations, aggression, gender, and testosterone. Proceedings of the Royal Society: Biological Sciences, 273. (pp. 2513-2520).

Keltner, D., Gruenfeld, D. H., \& Anderson, C. A. (2003). Power, approach, and inhibition. Psychological Review, 110, 265-284.

Kiesler, D.J. (1983). The 1982 interpersonal circle: Ataxonomy for complementarity in human transactions. Psychological Review, 90,185-214.

Lackner, J. M., \& Gurtman, M. B. (2004). Pain catastrophizing and interpersonal problems: A circumplex analysis of the communal coping model. Pain, 110, 597-604.

Leary, T. (1957). Interpersonal diagnosis of personality. New York: Ronald Press.

Litt, M. D. (1988). Self-efficacy and perceived control: Cognitive mediators of pain tolerance. Journal of Personality and Social Psychology, 54, 149-160.

Manning, M. M., \& Wright, T. L. (1983). Self-efficacy expectancies, outcome expectancies, and the persistence of pain control in childbirth. Journal of Personality and Social Psychology, 45,421-431.

McCaul, K. D., \& Malott, L. M. (1984). Distraction and coping with pain. Psychological Bulletin, 95, 516-533.

Mogil, J. S. (1999). The genetic mediation of individual differences in sensitivity to pain and its inhibition. Proceedings of the National Academy of Sciences, 96. (pp. 7744-7751).

Price, D. D. (2000). Psychological and neural mechanisms of the affective dimension of pain. Science, 288,1769-1772.

Schubert, T. W., \& Koole, S. L. (2009). The embodied self: Making a fist enhances men's power-related self-conceptions. Journal of Experimental Social Psychology, 45, 828-834.

Schubert, T. W., \& Semin, G. R. (2009). Embodiment as a unifying perspective for psychology. European Journal of Social Psychology, 39,1135-1141.

Smith, G. M., Egbert, L. D., Markowitz, R. A., Mosteller, F., \& Beecher, H. K. (1966). An experimental pain method sensitive to morphine in man: the submaximum effort tourniquet technique. Journal of Pharmacology and 
Smith, G. M., Lowenstein, E., Hubbard, J. H., \& Beecher, H. K. (1972). Experimental pain produced by the submaximum effort tourniquet technique: Further evidence of validity. Journal of Pharmacology and Experimental Therapeutics, 163,468-474.

Tiedens, L. Z., \& Fragale, A. R. (2003). Power moves: Complementarity in dominant and submissive nonverbal behavior. Journal of Personality and Social Psychology, 84,558-568.

Tiedens, L. Z., Unzueta, M. M., \& Young, M. J. (2007). An unconscious desire for hierarchy? The motivated perception of dominance complementary in task partners. Journal of Personality and Social Psychology, 93, 402-414.

Vaughn, K. B., \& Lanzetta, J. T. (1981). The effect of modification of expressive displays on vicarious emotional arousal. Journal of Experimental and Social Psychology, 17,16-30.

Wager, T. D., Rilling, J. K., Smith, E. E., Sokolik, A., Casey, K. L., Davidson, R. J., Kosslyn, S. M., Rose, R. M., \& Cohen, J. D. (2004). Placebo-induced changes in FMRI in the anticipation and experience of pain. Science, 303,1162-1167.

Wager, T. D., Scott, D. J., Zubieta, J. K., Wager, T. D., Scott, D. J., \& Zubieta, J. K. (2007). Placebo effects on human mu-opioid activity during pain. Proceedings of the National Academy of Sciences, 104. (pp. 11056-11061).

Wiggins, J. S. (1982). Circumplex models of interpersonal behavior in clinical psychology. In P. C. Kendall, \& J. N. Butcher (Eds.), Handbook of research methods in clinical psychology (pp. 183-221). New York: Wiley. 